\title{
РАЗРАБОТКА АЛГОРИТМА АВТОМАТИЗАЦИИ ПРИ ФОРМИРОВАНИИ КАРТОЧКИ ДОГОВОРНОГО ДОКУМЕНТА
}

\author{
(C) 2020 Денисенко Владислав Юрьевич \\ аспирант \\ Санкт-Петербургский государственный экономический университет, Россия, Санкт-Петербург \\ E-mail: vladizeslav@icloud.com
}

Предметом исследования является улучшение производственных связей, путем автоматизации рабочих процессов на предприятии. В статье рассматривается задача разработки организационного взаимодействия предприятия и контрагента через сайт zakupki.gov.ru для автоматизации процесса оформления карточки договорного документа на предприятиях. Предлагается алгоритм, который позволяет интегрировать в программное обеспечение автоматизацию процесса заведения карточки договорного документа. Указывается наличие двух мнений о характере влияния положительном и отрицательном, а также приводятся аргументы в поддержку данных позиций. Рассмотрены аспекты мнений руководителей предприятий в отсутствии необходимости введения автоматизации процессов, что ведет к приостановке развитии индустрии 4.0.

Ключевые слова: автоматизация, индустрия 4.0, киберфизические системы, информационные технологии, конкурентные преимущества, программное обеспечение, трудозатраты.

\section{Введение}

Использование цифровых технологий в настоящее время рассматривается, как один из ключевых драйверов социально-экономического развития. Международные исследования показывают положительное влияние внедрения цифровых технологий на производительность труда [3] [4], а также экономию ресурсов в различных секторах экономики [5]. Для формирования конкурентных преимуществ, предприятию необходимо развивать высокотехнологичные сферы по принципам Индустрии 4.0, активно развиваются такие направления как технология интернет вещей, облачные технологии, аддитивные технологии и другие.

Под конкурентными преимуществами предприятия понимаются его характеристики, которые предоставляют возможности получать высокий и стабильный экономический эффект, завоевывать большую долю рынка по сравнению с конкурентами [1]. В современном обществе информационные ресурсы рассматриваются, как экономическая категория и входят в состав основных ресурсов, которые используются любой организацией вместе с трудовыми ресурсами, капиталом, материалами, технологией и т.п. [2]

Постоянное совершенствование информационных технологий и их проникновение в разные сферы деятельности, также их применение позволяет достичь для предприятия ряд преи- муществ: экономия времени в сборе и получении информации для принятия стратегических решений, повышение производительности труда, снижение расходов, издержек, увеличение прибыли, развитие интеллектуального капитала. Для понимания значения интеллектуального капитала в цифровой экономике принципиально важно то, что при цифровизации информация превращается в ключевой ресурс экономики [6]. Применение ИКТ и получение нужной эффективности проявляется в ситуации, когда необходимо решить актуальные бизнес задачи, где применение технических, организационных или мотивационных мероприятий не способны решить необходимую задачу. Уже сейчас многие крупные предприятия не представляют свою деятельность без таких систем: электронный документооборот, корпоративные порталы, «интеллектуальные системы безопасности» и программные обеспечения ERP-системы (прим. SAP ERP).

Формирование карточки договорного документа.

Государственные предприятия в тендерной системе используют сайт «www.zakupki.gov.ru» при получении информации с сайта протокола работы комиссии о результатах на основе алгоритма действий, представленного на (рис. 1).

Данный алгоритм показывает операции сотрудника при создании новой карточки дого- 


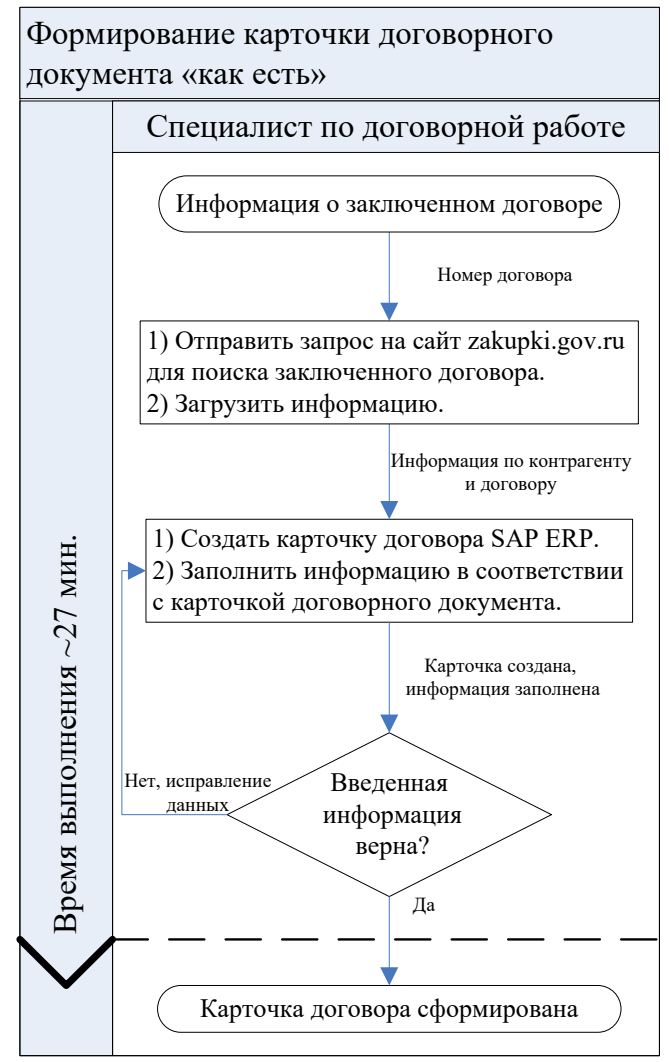

Puc. 1. Формирование карточки договорного документа «как есть» (Разработано автором)

ворного документа в программном обеспечении (прим. SAP ERP).

Выполнение операционной деятельности сотрудники сводятся к следующему:

1) Действия производятся в ручном режиме, из-за чего трудозатраты сотрудника используются неэффективно.

2) Данная работа требует особого внимания при заполнении информации о контрагенте, перепроверки внесенных данных, что приводит к увеличению времени обработки данных и перепроверки.

Организациям, заключающим договора через сайт zakupki.gov.ru приходится формировать карточки договоров в ручном режиме. Механический ввод информации имеет ряд отрицательных факторов, которые были описаны выше.

Время выполнения работы у опытного сотрудника занимает 30-35 мин., если информация о контрагенте отсутствует. При наличии информации о контрагенте выполнение операции занимает 20-25 мин.

Можно резюмировать, что автоматизация поможет решить ряд проблем. Алгоритм автоматизации карточки договорного документа представлен на (рис. 2):

В итоге процесс автоматизации предназначен для автоматизации договорных документов. Функции программы:

1. Поиск необходимых данных по заключенному договору.

2. Ввод данных карточки договорного документа.

3. Контроль оформления правильности карточки договорного документа и полноты пакета документов.

4. Формирование исполнительного дела контрагента согласно корпоративным требованиям.

При внедрении алгоритма автоматизации имеются, как положительные, так и отрицательные факторы, представленные в таблице 1.

Программа занимается автоматическим сбором, анализом, введение данных и осуществляет цикл перепроверки выполненных операций.

Эффект от реализации алгоритма заключается в улучшении управляемостью предприятием, повышением прозрачности труда и возможностью повышения производительности в 


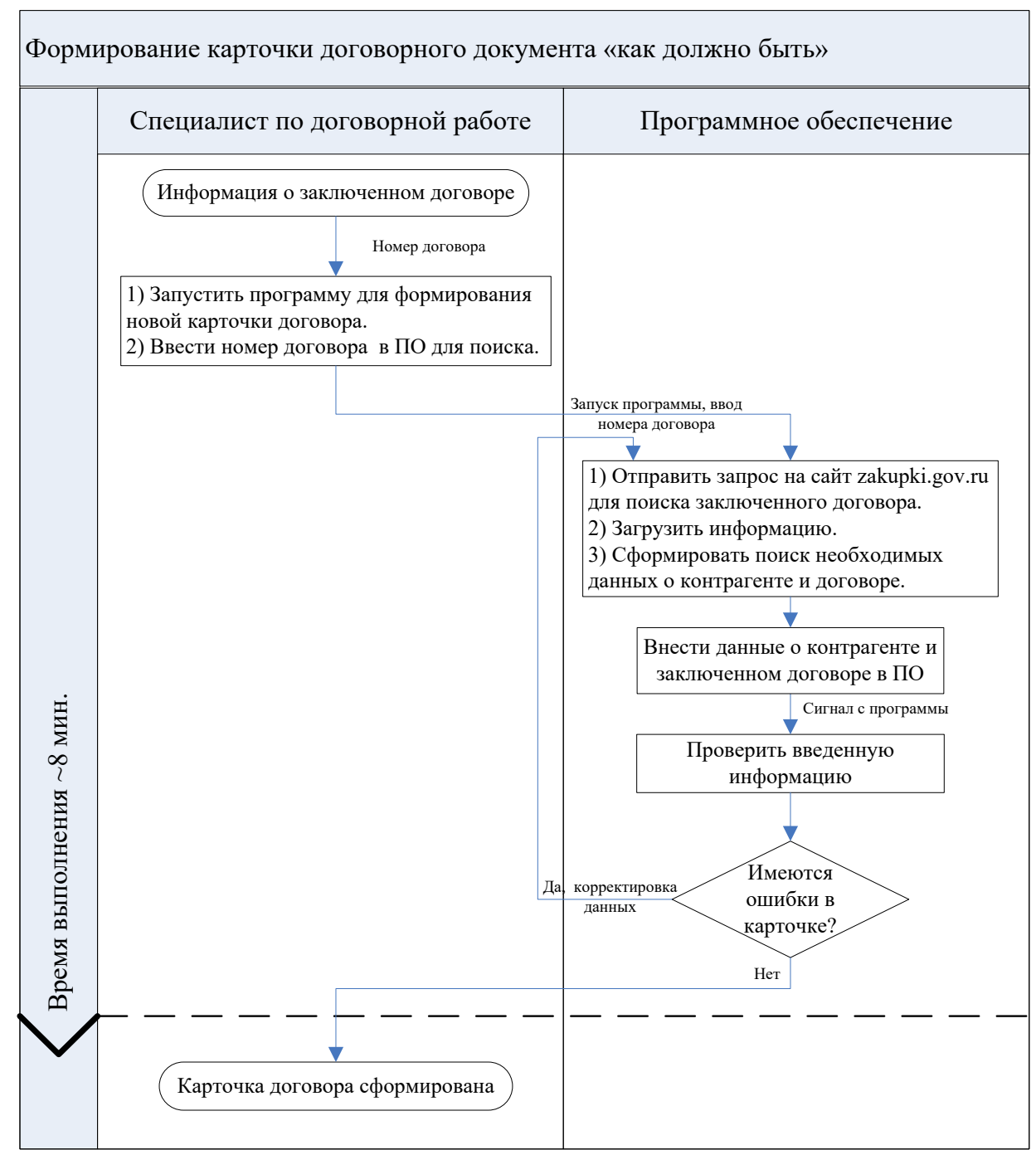

Puc. 2. Формирование карточки договорного документа «автоматизированный процесс» (Разработано автором)

Таблица 1. «Положительные и отрицательные стороны при внедрении автоматизации карточки договорного документа

\begin{tabular}{|c|c|}
\hline Положительные факторы воздействия & Отрицательные факторы воздействия \\
\hline $\begin{array}{l}\text { 1. Повышение скорости обработки данных сотрудником. } \\
\text { 2. Снижение количества ошибочных действий сотрудником. } \\
\text { 3. Сокращение времени на создание карточки договорного } \\
\text { документа. } \\
\text { 4. Снижение влияния роли человека на рабочий процесс. }\end{array}$ & $\begin{array}{l}\text { 1. Необходимость обучения сотрудников для } \\
\text { работы с ПО. } \\
\text { 2. Неспособность сотрудников адаптироваться } \\
\text { к новым условиям работы. }\end{array}$ \\
\hline
\end{tabular}


связи со снижением трудозатрат на выполнение операций.

Трудозатраты для реализации написания алгоритма и внедрения составляют примерно 28 часов, также понадобится переквалификация сотрудников, стоимость работ будет зависеть от трех основных факторов: используемого программного обеспечения, географического месторасположения и штата сотрудников, которых необходимо обучить. Для предприятий, заключающих от трехсот контрактов в год автоматизация карточки договорного документа поможет сократить затрачиваемое время от 95 часов и более.

Для предприятия с годовым оборотом $>150$ млн. рублей, стоимость оказания работ и услуг будет являться незначительной.

Снижение трудоемкости, исходя из данных на (рис. 1, рис. 2) на заведение одной карточки договора сократится в среднем на 19 минут. Раньше специалист за день оформлял 16 карточек договора, то при использовании программного обеспечения за день можно будет обрабатывать до 50 договоров, что говорит об увеличении производительности почти в 3 раза.

В сложившейся ситуации, автоматизация действующих процессов позволяет достичь конкурентных преимуществ, так как «реализация ресурсосберегающих мероприятий ведет к повышению эффективности и конкурентоспособности» [9].

Стоит выделить следующие внутрифирменные факторы по аналитической структуре ресурсно-ориентированного подхода для принятия решений об инвестировании в данную автоматизацию [7]:

1) Технологии и компетенции. Данные элементы взаимосвязаны, то есть компетенции необходимы для использования технологий, а организация процессов объясняет понимание использования ресурсов. Поэтому важно обладать компетенциями в области эксплуатации автоматизации производства, тогда можно будет использовать предназначенную технологию в соответствии с достижением желаемого результата.

2) Наличие уникальных ресурсов. Сложно данный алгоритм указать, как уникальный ре- сурс, если он реализован на одном предприятии с учетом сегмента рынка и географическим расположением, то он является уникальным ресурсом. Когда алгоритм начинает использоваться повсеместно на других предприятиях, то прекращает быть уникальным ресурсом. Необходимо управлять инновациями, так как это основа для поддержания эффективности и конкурентоспособности предприятия на высоком уровне [8].

\section{Заключение}

Каждая потребность, сформированная в процессе деятельности человека, привела нас к информационно-технологической революции, как следствие диффузии ИКТ на всех уровнях жизнедеятельности. По мнению автора можно сделать вывод о необходимости развития киберфизических систем на предприятии, т.к. «компании должны постоянно повышать операционную эффективность всех видов деятельности, но устойчивые различия в производительности будут зависеть от наличия отличной стратегической позиции» [10]. Быстрая адаптация под развивающиеся киберфизические системы помогает достичь на определенный этап улучшения своих позиций на рынке, но нельзя забывать об увеличении объема информационных данных, что в свою очередь может привести к перегрузкам систем, поэтому необходимо постоянно контролировать, анализировать и применять обновленные серверы для хранения данных, чтобы не происходили возможные сбои.

Переход предприятий к Индустрии 4.0, ориентирован в первую очередь на минимальное участие человека в производстве. Во многих странах, в том числе и в Российской Федерации переход к новому укладу складывается непросто, в первую очередь из-за позиций руководителей предприятий и структурных подразделений, причем в большой степени это касается организаций финансируемых из бюджета регионов/ государства, данная тенденция существует из-за недоверия и привычки работать по «заезженным» процессам. Проблема является актуальной для исследований и развития в части автоматизации производственных операций и преодоления психологического барьера у руководства промышленных предприятий для внедрения киберфизических систем. 


\section{Библиографический список}

1. Информационно-аналитическое сетевое издание «ПРОВЭД». URL: http://провэд.pф/economics.html. (дата обращения 18.06.2019)

2. Государственная программа развития сельского хозяйства и регулирования рынков сельскохозяйственной продукции, сырья и продовольствия на 2013-2020 годы // Официальный сайт Минсельхоза Poccuи. URL: http:// mcx.ru.

3. Brynjolfsson E., Hitt L.M., Kim H.H. Strength in Numbers: How Does Data - Driven Decision making Affect Firm Performance? // Social Science Research

4. Brynjolfsson, Erik and Hitt, Lorin M. and Kim, Heekyung Hellen, Strength in Numbers: How Does Data-Driven Decisionmaking Affect Firm Performance? (April 22, 2011). Available at SSRN: https://ssrn.com/abstract=1819486 (дата обращения 18.01.2020 г.).

5. Barua A., Mani D., Mukherjee R. Impacts of effective data on business innovation and growth. University of Texas at Austin. http://www.businesswire.com/news/home/20100927005388/en/Sybase-University-Texas-Study-RevealsIncremental-Improvements.

6. Citigroup-Oxford Martin School. Technology at Work: The Future of Innovation and Employment. 2015.

7. Carl Benedikt Freyt and Michael A. Osborne // The future of employment: how susceptible are jobs to computerisation?/ September 17,2013 https://www.oxfordmartin.ox.ac.uk/downloads/academic/future-ofemployment.pdf. (дата обращения 15.01.2020 г.)

8. Карлик А. Е., Платонов В.В., Яковлева Е. А., Павлова О.С. Модифицированный навигатор интеллектуального капитала для принятия решений в информационно-сетевой экономике // МИР (Модернизация. Инновации. Развитие). 2018. Т. 9. № 3. С. 338-350. DOI: 10.18184/2079-4665.2018.9.3.338-350.

9. Карлик А., Платонов В. Аналитическая структура ресурсно-ориентированного подхода. Часть $1 / /$ Проблемы теории и практики управления. 2013. № 6-7. С. 26-37.

10. Портер, Майкл, Э. Конкуренция.: Пер. с англ. М.: Издательский дом «Вильямс», 2005.-608 с.: ил - Парал. тит. англ. 